\title{
Ekonomika Pasar-Populis
}

\section{Mubyarto}

Reformation and it's process shows us that Indonesia has lost it's direction in maintaining economical situation. Pancasila economic system, is still become our economic paradigm, referring to chapter 33 of amended constitution of 1945. Koperasi (corporation) as the pillar for Pancasila economic system, still unable to answer economic challenges for the future. The unclear direction of economic development, actually is caused by the ignorance of people toward ideas which is relevant to be grown in the context of Pancasila economic system. With only catching the surface of this economic system, impossible for Indonesian people to think deeply and maturely toward this economic system itself. Thus, this is the real question which must be addressed in the future coming.

\section{Kata-kata kunci: ekonomi pasar neoliberalisme, koperasi}

The importance to Smith of the overall set of values in which the economy operates is generally ignored by his followers in the late twentieth century. His economics, based upon individual selfinterest, is remembered, but his moral framework is not. (Ormerod 1994 : 14) ika benar "ramalan" banyak orang bahwa ekonomi dan kebijakan ekonomi Indonesia tak akan berubah meskipun Capres/Cawapres yang menang adalah yang "menjanjikan perubahan", namun akan tetap menarik mengamati dalam hal-hal apa saja perubahan "pasti" terjadi. Salah satu perubahan yang mungkin dapat "diramal" akan terjadi adalah bagaimana pemerintah (dan massyarakat) melihat fenomena pasar. Jika di masa lalu, khususnya selama masa "transisi" sejak krismon 1997/1998, pemerintah harus "bersahabat" dengan pasar (market friendly), mest ipun dalam kedudukan tidak berdaya ("if we can not beat them, join them'), kiranya pemerintah yang akan datang harus bersikap lain, yaitu harus berani menyatakan tidakjika jelas berjalannya mekanisme pasar yang terlalu bebas justru mengancam ketahanan ekonomi nasional kita. Sikap yang "lebih berani" juga diperlukan pemerintah dalam menghadapi "tekanan-tekanan" WTO, AFTA, dan APEC menyangkut impor dan ekspor komoditi-komoditi perdagangan inter-nasional, misalnya dalam komoditi beras dan gula.

Sikap pemerintah yang tidak lagi gampang menyerah pada tekanan kepentingan ekonomi dari luar yang dapat merugikan kepentingan ekonomi nasional inilah yang akan menandai perubahan kebijakan ekonomi Indonesia. Pasar tidak lagi dijadikan pedoman arah kebijakan tetapi justru dijadikan "alat" untuk memajukan kepentingan ekonomi nasional dan mewujudkan keadilan sosial. Misalnya sudah mulai diperdengarkan peringatan "Presiden terpilih harus menganut Ekonomi Pasar", bukan "ekonomi komando", atau pemerintah baru harus menepati janji menarik investasi (asing) melalui berbagai perangsang (incentive) perpajakan dan lainlain. Bahkan lebih tegas lagi diingatkan agar pemerintah "jangan mengambil kebijakankebijakan populis, yang bertentangan dengan asas-asas efisiensi". "Kebijakankebijakan pemerintah harus "pro-bisnis" ", 
dan lain-lain. Peringatan-peringatan seperti ini jelas merupakan "ujian" dan saya khawatir sekaligus "perangkap" bagi pemerintah apakah akan sanggup melaksanakan kebijakan-kebijakan ekonomi yang "prokeadilan" dan "pro-Pancasila", ekonomi Pancasila.

\section{Ilmu Ekonomi Moral}

Sejak "kemenangan gilang-gemilang" paham kapitalisme terhadap paham sosialisme yang ditandai dengan ambruknya negara adikuasa "Uni Soviet" tahun 1991, pakar-pakar ekonomi pada umumnya makin memuja pada apa yang dikenal sebagai sistem ekonomi pasar bebas. Bahkan 2 tahun sebelumnya, dicetuskan "Konsensus Washington" (1989) yang menandai makin merebaknya paham Neoliberalisme. Paham neoliberal menghendaki makin dikuranginya peranan pemerintah dalam perekonomian dengan contoh kongkritnya anjuran meningkatkan privatisasi perusahaanperusahaan yang sebelumnya dikuasai atau dimiliki negara.

Di Indonesia privatisasi makin gencar dilaksanakan karena krisis moneter (krismon) tahun 1997/1998 telah membuat keuangan pemerintah "kocar-kacir", sehingga DPR mengizinkan "penjualan obral" BUMN yang dikelola BPPN untuk menutup defisit anggaran negara. Maka dibentuk Kementerian Negara Khusus Urusan BUMN yang bertugas menjual BUMN di pasar modal, sehingga banyak BUMN yang kemudian dikuasai investor dari luar negeri. Inilah awal dari keprihatinan dan kekhawatiran serius bahwa amanat konstitusi khususnya pasal 33 UUD 1945 dilanggar dengan mudah yang berakibat tertindasinya rakyat banyak.

- Dalam pasal 33 tercantum dasar demokrasi ekonomi, produksi dikerjakan oleh semua untuk semua di bawah pimpinan atau pemilikan anggota-anggota masyarakat. Kemakmuran masyarakatlah yang diutamakan, bukan kemakmuran orangseorang. Sebab itu perekonomian disusun sebagai usaha bersama berdasar atas azas kekeluargaan. Bangunan perusahaan yang sesuai dengan itu ialah koperasi.

Perekonomian berdasar atas demokrasi ekonomi, kemakmuran bagi semua orang. Sebab itu cabang-cabang produksi yang penting bagi Negara dan yang menguasai hidup orang banyak harus dikuasai oleh Negara. Kalau tidak, tampuk produksi jatuh ke tangan orang-seorang yang berkuasa dan rakyat yang banyak ditindasinya.

Hanya perusahaan yang tidak menguasai hajat hidup orang banyak boleh di tangan orang-seorang."

1 Penjelasan Pasal 33 UUD 1945. Pasal ini oleh Komisi Konstitusi diusulkan menjadi pasal 68 (bab XVIII) dengan perubahanperubahan sangat mendasar berikut: (1) Perekonomian disusun sebagai usaha bersama berdasar atas asas kekeluargaan untuk sebesar-besar kemakmuran rakyat. (2) Cabang-cabang Produksi yang penting bagi negara dan yang menguasai hajat hidup orang banyak dikuasai dan diatur oleh negara. (3) Seluruh kekayaan alam dan lingkungan yang terkandung dalam wilayah kedaulatan, hak-hak berdaulat dan kewenangan Indonesia, baik di darat, di laut, termasuk dasar laut dan tanah di bawahnya, serta udara di atasnya, dikuasai dan diatur oleh negara berdasarkan peraturan perundang-undangan, dan dipergunakan untuk sebesar-besar kemakmuran rakyat. (4) Perekonomian diselenggarakan berdasarkan asas demokrasi ekonomi, efisiensi, dan keadilan serta berwawasan lingkungan. (5) Negara memajukan dan memberdayakan semua pelaku ekonomi secara seimbang dan berkelanjutan. 


\section{Dari Krisis Ekonomi ke Krisis Teori Ekonomi}

Kalangan orang-orang awam sering bingung, mengapa para teknokratyang telah menjadi "pahlawan pembangunan ekonomi" pada dan selama 32 tahun Orde Baru, kini nampak "tidak berdaya" menyusun kebijakan-kębijakan ekonomi serupa untuk menyelamatkan "keterpurukan ekonomi indonesia" yang terkena krisis moneter (krismon) sejak 1997/1998. Selanjutnya ada kesan kuat telah terjadinya "pengulangan sejarah". Indonesia mengundang pakarpakar ekonomi kaliber dunia (IMF, IBRD, dan UNSFIR) untuk membantu mengatasi "kekacauan" ekonomi-keuangan-perbankan yang terjadi. Bahkan lebih tragis lagi jika sering timbul kesan, pakar-pakar ekonomi Indonesia rupanya harus mengakui "lebih bodoh" ketimbang pakar-pakar ekonomi asing dalam kemampuan menganalisis masalah-masalah ekonomi Indonesia, padahal pakar-pakar ekonomi asing yang "menasehati" pakar-pakar kita itu, sebenarnya "tidak cukup paham" tentang ekonomi Indonesia.

Pada tahun 2002, bersama rekan Daniel Bromley dari Universitas Wisconsin, kami mengkonstatasi bahwa pakar-pakar ekonomi Indonesia yang memperoleh pendidikan tinggi dalam ilmu ekonomi "Mazhab Amerika", setelah pulang ke negerinya dengan membawa peralatan teori ekonomi yang abstrak, serta merta menyusun rekomendasi dan menerapkan kebijakan ekonomi yang menghasilkan pertumbuhan ekonomi, sekaligus mengira bahwa pertumbuhan ekonomi itu juga mampu memberikan kesejahteraan dan kebahagiaan pada seluruh bangsa dan rakyat Indonesia. $^{2}$

Anggapan keliru bahwa pertumbuhan ekonomi secara otomatis memberikan kesejahteraan dan kebahagiaan kepada seluruh rakyat inilah yang kemudian membuat mereka (teknokrat) bersikukuh bahwa krisis dalam bidang ekonomikeuangan yang (dianggap) masih berlangsung dewasa ini pasti dapat diobati dengan resep-resep yang sama juga yaitu kebijakan liberalisasi (lebih jauh) dan deregulasi seperti pada awal Orde Baru. Keyakinan yang berlebihan akan "kebenaran" teori-teori ekonomi konvensional (Barat) inilah yang pada hemat kami justru menjadi sebab utama tidak teratasinya "krisis-ekonomi" dewasa ini. Kami berpendapat bahwa sebenarnya Indonesia dewasa ini tidak lagi mengalami "krisisekonomi", tetapi menghadapi "krisis ilmu ekonomi". Artinya, kita tidak mungkin dapat keluar dari krisis yang kita hadapi jika tidak bersedia mengkaji ulang seluruh teori ekonomi konvensional Barat. Teori-teori ekonomi ini memang benar-benar telah menguasai pikiran pakar-pakar ekonomi arus utama dan dijadikan pegangan perumusan kebijakan dan strategi pembangunan ekonomi Indonesia selama 3 dekade.

Sejak ilmu ekonomi menjadi sangat spesialistis dan "dipisahkan" dari induknya yaitu ilmu sosial dan ilmu moral (khususnya oleh Paul Samuelson dan Lionel Robbins), terutama dengan digunakannya matematika (ekonometri), ilmu ini memang terasa makin "kering", "tidak realistis" dan makin "tidak relevan". Itulah sebabnya di Amerika terbit buku Is Economics Relevant? (Heilbroner \& Arthur Ford, 1971), dan What's Wrong With Economics (Benjamin Ward, 1972). Meskipun demikian, terbitnya buku-buku ini

${ }^{2}$ Mubyarto \& Daniel W. Bromley, 2002, A Development Alternative for Indonesia, Gadjah Mada University Press, Yogyakarta. 
tetap saja tidak mampu menghentikan kecenderungan makin menjauhnya ilmu ekonomi dari ilmu-ilmu sosial dan moral tersebut.

Sebenarnya, Alfred Marshall, selain tokoh ekonomi kebetulan juga ahli matematika, telah mengingatkan para ekonom untuk tidak kebablasan menggunakan matematika murni dalam analisisanalisis ekonomi. Matematika lebih tepat digunakan ekonom "untuk keperluan sendiri", tidak untuk "mengintimidasi" pihak-pihak lain.

The chief use of pure mathematics in economic questions seems to be in helping a person to write down quickly, shortly, and exactly, some of his thoughts for his own use. (Marshall, 1890: $x)$

(Penggunaan utama dari matematika murni dalam pertanyaan-pertanyaan ekonomi adalah untuk membantu seseorang menulis secara cepat, singkat, dan tepat, pikiran-pikirannya untuk keperluan sendiri).

Pada tahun 1988 terbit buku Amitai Etzioni, The Moral Dimension: Toward a New Economics, dan tahun 2001 terbit buku Robert Nelson Economics as Religion. Kedua bukú ini menentang keras ajaran ekonomi Neoklasik yang laksana "ajaran agama" yang sulit dibantah "dogmanya" dengan penelitian-penelitian ilmiah, baik yang bersifat kuantitatif maupun kualitatif. Kebanyakan ekonom Indonesia tidak tahu, atau tidak mau tahu, kehadiran buku "Anti Samuelson" oleh Marc Linder yang terbit dalam 2 jilid (Macroeconomics dan Microeconomics) tahun 1977.

Kini, kita di Indonesia, sudah makin diyakinkan betapa ilmu ekonomi ortodok yang terlalu berat mengajarkan "keserakahan atas alam benda" itu; tidak mampu membantu bangsa Indonesia mengatasi masalah-masalah ekonomi-sosial-moral yang melanda bangsa sejak krismon 1997.I 1998. Maka kita yang sempat belajar ilmu ekonomi harus berusaha keras mengembangkan ajaran ilmu ekonomi baru yang lebih realistis, lebih relevan, dan lebih populis, bagi kehidupan bangsa Indonesia (real-economic life), dan dapat dipakai untuk memecahkan masalah-masalah ekonomi yang sudah menjadi sangat komplek dan yang tidak mungkin lagi dipecahkan ilmu ekonomi sendiri, khususnya ilmu ekonomi Neoklasik konvensional.

Pakar-pakar ekonomi perlu menyadari tantangan besar krisis teori ekonomi yang kini dihadapi Indonesia. Kita harus bekerja keras, dan lebih banyak lagi mengadakan kajian-kajian yang dapat menghasilkan gagasan-gagasan brilyan bagi pengem- bangan ilmu ekonomi baru di sekolahsekolah dan perguruan tinggi kita. Ilmu ekonomi baru ini adalah ilmu ekonomi Pancasila, yaitu ilmu ekonomi pasar yang populis, yang taat mematuhi "jiwa" kelima asas Pancasila, dan setia pada filsafat Pancasila secara utuh yaitu kekeluargaan dan gotong-royong.

\section{IImu Ekonomi Koperasi}

Kita yakin bahwa ilmu ekonomi ortodok konvensional (Neoklasik) yang berasal dari Barat "manfaatnya sangat terbatas", atau "tidak relevan" untuk Indonesia. Bahkan seandainya kita tidak merasa perlu mengaitkan ilmu ekonomi dengan ideologi bangsa Indonesia yaitu Pancasila (Ekonomi Pancasila), ilmu ekonomi Barat tidak dapat dijadikan alat (tool) untuk membantu manusia Indonesia memenuhi kebutuhan sosialnya. Karena sudah jelas kebutuhan manusia (Indonesia) tidak hanya kebutuhan ekonomi materiil saja, tetapi juga kebutuhan 
sosial (dan etik), maka ilmu ekonomi yang harus dipelajari dan diajarkan di Indonesia adalah ilmu ekonomi koperasi (social economics, bukan economics). Setiap orang (Indonesia) tidak mungkin hidup sendiriatau hanya memikirkan diri sendiri. la harus selalu berpikir dan berbuat dengan juga memikirkan orang lain. Orang harus hidup bermasyarakat. la harus selalu bekerjasama dengan orang lain. Di pasar si penjual perlu pembeli agar terjadi transaksi jual beli. ini berarti ada kerjasama bukan persaingan antara penjual dan pembeli.

IImu ekonomi koperasi, berbeda dengan ilmu ekonomi ortodok, mengajarkan cara-cara bekerjasama bukan cara-cara bersaing. Bersaing dapat mencapai efisiensi tetapi bekerja sama juga dapat menghasilkan efisiensi tinggi. Jadi, kalau dalam ilmu ekonomi ortodok hanya dikenal modelmodel persaingan sempurna, kepada siswa dan mahasiswa harus diajarkan juga modelmodel kerjasama (sempurna maupun kerjasama yang kurang sempurna). Ilmu apa asal tambah kerabat". Ilmu ekonomi yang diajarkan di Indonesia harus $/ I m u$ Ekonomi Koperasi, bukan ekonomika matematik.

Orang banyak sering bertanya-tanya, apanya yang salah dalam pengembangan koperasi di Indonesia. Mengapa GKBI (Gabungan Koperasi Batik Indonesia) yang pernah berjaya kini tidak lagi berperanan dalam perekonomian Indonesia, khususnya dalam industri batik? Mengapa koperasi pertanian atau KUD yang didukung resmi melalui kebijakan pemerintah dengan berbagai sarana dan kemudahan kini tinggal nama saja?

Sebenarnya tidak sepenuhnya benar kalau dikatakan bahwa di Indonesia tidak ada koperasi yang dapat disebut berhasil. Sejak krismon 1997/1998 ada satu contoh koperasi di Yogyakarta yaitu KOSUDGAMA (Koperasi Serba Usaha Dosen-dosen Gadjah Mada) di kampus UGM, yang telah berkembang luar biasa.

Tabel 1. Nilai Pinjaman, Jumlah Peminjam, dan Jumlah Anggota KOSUDGAMA, 1998-2003

\begin{tabular}{|c|c|c|c|c|c|}
\hline Tahun & $\begin{array}{c}\text { Nilai } \\
\text { Pinjaman } \\
\text { (Juta Rp) }\end{array}$ & $\begin{array}{c}\text { Pertumbuhan } \\
(\%)\end{array}$ & $\begin{array}{c}\text { Jumlah } \\
\text { Peminjam } \\
\text { (Orang) }\end{array}$ & $\begin{array}{c}\text { Jumlah } \\
\text { Anggota } \\
\text { (Orang) }\end{array}$ & $\begin{array}{c}\text { Pertumbuhan } \\
\text { (\%) }\end{array}$ \\
\hline 1998 & $1.036,75$ & & 422 & 1010 & \\
\hline 1999 & $2.872,19$ & 177 & 822 & 1471 & 46 \\
\hline 2000 & $6.498,70$ & 126 & 1.514 & 2798 & 90 \\
\hline 2001 & $7.311,88$ & 13 & 1.478 & 4063 & 45 \\
\hline 2002 & $11.569,25$ & 58 & 1.936 & 5332 & 31 \\
\hline 2003 & $16.968,40$ & 47 & 2.050 & 6473 & 21 \\
\hline
\end{tabular}

Sumber : Laporan Tahunan RAT XXII Tahun 2003

ekonomi koperasi berasaskan kekeluargaan, dan disesuaikan dengan pelaksanaan ajaran pepatah Jawa "tuna satak bathi sanak", yang berarti "rugi sedikit tidak apa-
Terlihat dari tabel 1 bahwa selama periode 1998 - 2003 jumlah anggota KOSUDGAMA meningkat lebih dari $5 \mathrm{kali}$ lipat, pinjamannya meningkat 17 kali lipat, 
dengan túngggakan yàng hanya $0,3 \%$ !: Kunci atau" rahasia”" keberhasilan:KOSUDGAMA ádalah bahwa kegiatan=kegiatannya hàrus dibutuhkañánggotai'dan selaluin uñtuk melayani anggōta: Pengurús'koperasi sama 'sekalit tidak' boleh melanggar mandat RAT!

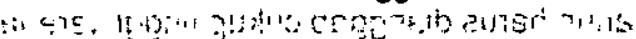

:Keterpúrukan' Ekonomi IIndonesia - Ken when - Ada s su ekonom penting yang sering diajukan masyarakat di ndonesia -1. Mengapa krisis ekonomi tak kunjung selesai? = th zib an: ara imron-

2. - Mengapa, kapitalisme menjadi

$\therefore$ : "tuhannya" bangsa Indonesia? r.

3. Mengapa pasar - bebas ditentang banyak wargarmasyarakat? it i...:

4.. Mengapa: konglomerat melarikan .... . modalnya keluar negeri? int. . in

$5 .$, Mengapa:privatișasistidak dihentikan meskipun bertentangan dengan amanat

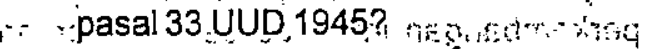

6. Mengapa sektor perbankan-,propertiti dan manufaktur kita hancur?

7. Mengapa kemiskinan, pengangguran, ketimpangan ekonomi, dan kesenjangan sosial menajam?

8. Mengapa pembangunan ekonomi indonesia tertinggal dibanding negarä:s: negara ASEAN lainnya?

Terhadap 8 isu ini ilmu ekonomi konvensional yang diajarkan di sekolahsekolah dan perguruan tinggi kita benarbenar tidak mampu menjawab secara. konklusif, yang dapat disetujui sebagiän besar pakar ekonomi. Halvinizdišebäbkan ilmu ekonomi konvensional mempunyai kelemahan mendasar sehingga pernah dikritik secara pedas sebagai berikut:

One of the difficulties of economics is that it is too easy to explain after a particular event have happened why it should have happened and too easy to explain before it happen, why' it is I should not happen's(Kendalf,:M:G:

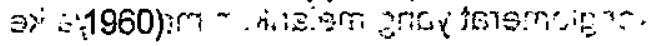

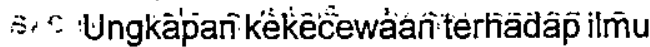

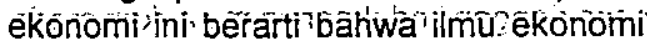

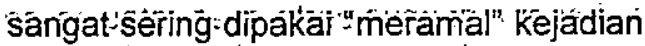

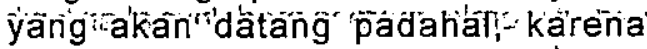
digunakan asumsi-asumsi' 'yâning' tidäk terpenuhic ia sebenarnya tidakmemiliki kemampuan melakukan:ramalan-ramalan itu Konsekuensinya, tidak pernah ada:kata šepakat dijantara.pakar-pakar.ekonomi; apa yang, akan:terjadi bila, suatu; kebijakan ékonomi tertentu diambil:pemerintah:

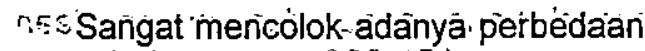

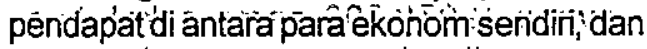

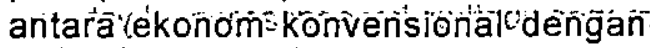

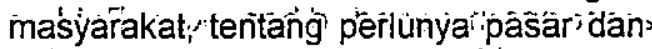

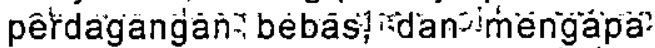
kébijakan privàtisasisi'dikembängkan -tànina”

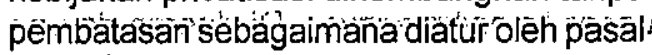

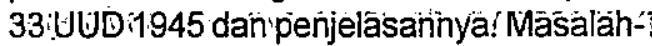
nya; Cdalami'kenyataàn 'selalü 'áda yàng:

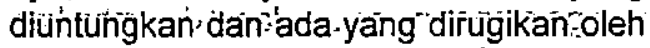
suatu 'kebijakan, 'sehingga äkèpentingan ékönómi šiäpa yâng paling páñdai dan? berhasil melobi pengambil kebijakan,

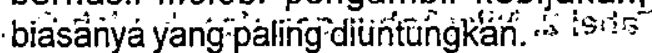

- Siapa yang menganggap kapitalisme sebagai tuhan? Tentu saja méreka yang sangat diuntungkan yaitu para ka pitalis yang tidak pernah mau dikéndálikan "kèserá-1 kahannya Bahwa Ir. Sóekarno padajtahún

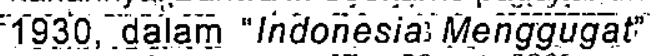
menggerakkan rakyat Iñonesia úntuk merubuhkan kapitalisme dán imperialisisme. tetapi kiñi setelah̀ Tñōnēsia mérdèka 59

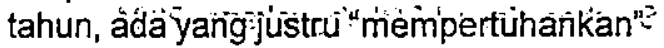
kapitalisme, tentulah karena sekarang ada "räkyät" yaang sudah meienjadi "kapitälis",ỳang ménighendaki ditumbuhkeminbang gannyapahiam ${ }^{\hat{t}}$ kapitalisme it itu Privatisa'si ädalah salah'šatu bentuk dàn càràimengembang- : kan 'kapitališme sehingga pasti didukung'

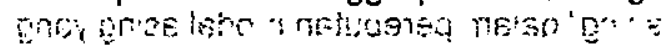


"rakyat" kapitalis itu. Demikian pula konglomerat yang melarikan modalnya ke luar negeri (capital flight) adalah mereka yang dengan tindakannya melarikan modal itu keuntungannya bertambah, atau paling sedikit mereka merasa modalnya akan lebih aman/terjamin.

Tentang krisis ekonomi sebagaimana "dibuktikan" dengan hancurnya sektor perbankan, properti, dan manufaktur, yang mengakibatkan meningkatnya kemiskinan dan pengangguran, apa yang sering diberitakan di media massa sebenarnya banyak bertentangan dengan kenyataan. Krismon 1997/1998 sama sekali tidak mengakibatkan kesengsaraan rakyat yang amat parah seperti diberitakan. Bahkan sektor-sektor pertanian, perikanan, dan perkebunan rakyat, banyak yang benarbenar "menikmatinya". Di daerah-daerah perdesaan pada umumnya ekonomi rakyat justru berkembang dengan baik, sebagaimana antara lain dapat digambarkan dari kenaikan kesejahteraan rakyat di Propinși DIY, selama 1997-2003 (Tabel2). memang menghendaki "jaminan keamanan" yang tinggi bagi mereka. Investasi asing baru di Indonesia dewasa ini memang rendah, tetapi ini tidak berarti tidak ada lagi investasi yang masuk ke Indonesia. Bahwa ekonomi Indonesia kini mampu tumbuh $4-5 \%$ per tahun harus dianggap cukup tinggi karena pertumbuhan ekonomi ini disumbang oleh ekonomi rakyat yang data-data pendukungnya masih sulit dihitung. Sektor informal di Indonesia merupakan $64,1 \%$ (2002) yang berarti hanya kira-kira sepertiga kegiatan ekonomi yang dapat didata dengan baik. Artinya kegiatan ekonomi sektor formal yang dilaporkan telah "hancur" justru telah memberikan peluang besar bagi sektor informal untuk berkiprah. Inilah yang menerangkan mengapa "krisis ekonomi" yang dikatakan berkepanjangan sebenarnya tidak didukung data-data riil karena ekonomi rakyat sebenarnya cukup berkembang, dan perkembangan ini lepas dari pendataan resmi BPS dan dinas-dinas pemerintah daerah.

Tabel 2. Nilai Tabungan dan Jumlah Penabung di BRI di Propinsi DIY, 1997 - 2003

\begin{tabular}{|c|c|c|c|c|c|}
\hline Tahun & $\begin{array}{c}\text { Penabung } \\
\text { (Orang) }\end{array}$ & $\begin{array}{c}\text { Perubahan } \\
(\%)\end{array}$ & $\begin{array}{c}\text { Nilai } \\
\text { (Milyar Rp) }\end{array}$ & $\begin{array}{c}\text { Perubahan } \\
(\%)\end{array}$ & $\begin{array}{c}\text { Rata-rata tabungan } \\
\text { per orang }\end{array}$ \\
\hline Des. 1997 & 457.496 & & 263,02 & & $\mathbf{5 7 4 . 9 1 2}$ \\
\hline Des. 1998 & 554.354 & 21,2 & 435,72 & 65,7 & $\mathbf{7 8 5 . 9 9 6}$ \\
\hline Des. 1999 & 630.708 & 13,8 & 531,36 & 22,0 & $\mathbf{8 4 2 . 4 8 2}$ \\
\hline Des. 2000 & 668.324 & 6,0 & 568,87 & 7,1 & $\mathbf{8 5 1 . 1 8 9}$ \\
\hline Des. 2001 & 887.631 & $\mathbf{3 2 , 8}$ & 740,19 & 30,1 & $\mathbf{7 3 3 . 8 9 4}$ \\
\hline Des. 2002 & 950.978 & $\mathbf{7 , 1}$ & 787,76 & 6,4 & 828.368 \\
\hline Des. 2003 & 1.027 .829 & 1,3 & $1.300,83$ & 65,1 & 1.265 .609 \\
\hline Rata-rata & & $\mathbf{1 3 , 7}$ & & $\mathbf{3 2 , 7}$ & \\
\hline
\end{tabular}

Sumber: Kanwil BRI Yogyakarta, 2004

Akhirnya mengenai ketertinggalan pembangunan ekonomi Indonesia dibandingkan sejumlah negara tetangga ASEAN juga tidak sepenuhnya benar, kecuali jika yang dibandingkan adalah "daya saing" dalam perebutan modal asing yang
Pemerintah tidak seyogyanya menutup mata pada fakta-fakta perkembangan ekonomi rakyat yang "luar biasa" sejak krismon. Dewasa ini satu-satunya sektor ekonomi yang masih mengalami krisis adalah "sektor" APBN, itupun bukan karena 
penerimaan pemerintah merosot, tetapi lebih karena pemerintah masih tersandera ekskonglomeratyang "berpura-pura hancur" dan merengek-rengek minta perusahaannya "diselamatkan" oleh pemerintah. Memang harus diakui amat tidak mudah mengubah sikap dan kebijakan pemerintah yang berpihak pada konglomerat menjadi berpihak pada ekonomi rakyat.

\section{IImuwan dan Pembangunan}

Berbagai uraian yang diajukan di sini merupakan upaya utuk menjawab pertanyaan sederhana dari masyarakat mengapa Indonesia yang sudah memiliki ratusan ribu sarjana dari berbagai cabang keilmuan termasuk ilmuwan ekonomi rupanya belum mampu menghasilkan gagasan-gagasan "hebat" dan "orisinil" untuk mengatasi krisis multidimensi yang kita hadapi. Bahkan sering orang dengan sedih mengingatkan kehadiran Profesor Dr. B.J. Habibie yang cemerlang sebagai Presiden Indonesia ke-3, tokh hanya mampu bertahan 17 bulan memimpin bangsa, tanpa sempat menerapkan ilmu pengetahuan canggih yang dikuasainya untuk memecahkan berbagai masalah yang dihadapi bangsa Indonesia.

Memang sangat tepat apa yang pernah diingatkan Profesor Dr. Sardjito, Rektor pertama dan pendiri UGM, bahwa spesialisasi ilmu yang terlalu jauh tidak saja tidak perlu, tetapi justru dapat berbahaya, karena tidak mempersatukan orang atau ilmuwan untuk bekerja sama, tetapi sebaliknya dapat memisahkan, dan justru bersaing satu sama lain untuk saling menjatuhkan.

It is being realized that too strong a trend toward specialization may be a dangerous thing for society. It is to be noted that an educational program de- voted almost exclusively to specialization is likely to have the effect of separating people from people, not of bringing them together (Thayer 1959 dalam Mubyarto, 2004:160).

(Disadaribahwa kecenderungan yang terlalu jauh ke arah spesialisasi mungkin berbahaya bagi masyarakat. Harus dicatat bahwa satu program pendidikan yang diarahkan secara eksklusif pada spesialisasi sangat mungkin berakibat memisahkan orang yang satu dari yang lain, bukan menyatukannya).

Bahaya itulah yang benar-benar telah kita saksikan dan terjadi di Indonesia dalam bidang ilmu ekonomi. Dewasa ini ilmu ekonomi sudah direduksi menjadi ilmu manajemen dan ilmu akuntansi, yang keduanya sering tidak lagi merasa merupakan bagian dari ilmu sosial dan ilmu moral, karena dianggap sekedar alat mengelola perusahaan modern.

Sekarang banyak berdiri Sekolah Tinggi Ilmu Ekonomi (STIE) tetapi hanya memiliki jurusan manajemen dan akuntansi, dan Fakultas-fakultas Ekonomi di Universitas pun sudah mulai memisahkan ketiga jurusan (ekonomi, manajemen, dan akuntansi) pada tahun pertama. Akibatnya sarjana-sarjana ekonomi yang diluluskan sulit dianggap sebagai sarjana (ilmu) ekonomi yang benar-benar memahami ilmu ekonomi sebagai ilmu sosial dan ilmu moral. Maka ilmu yang dikuasai para alumninya sekedar "ilmu" bagi kepentingan dirinya sendiri atau hanya untuk "bekerja pada orang lain/perusahaan", bukan untuk diabdikan pada pembangunan masyarakat dan bangsanya.

Pendidikan dan pengajaran tinggi bermaksud memberi kesempatan kepada pelajar untuk menjadi orang yang dapat memberi pimpinan dalam masyarakat dan 
yang dapat memelihara kemajuan hidup kemasyarakatan (Sardjito dalam Mubyarto, 2004: 152).

Pendidikan dan pengajaran ilmu di Perguruan-perguruan tinggi kita harus diperbaharui bahkan di "revolusi" sehingga dapat menghasilkan ilmuwan-ilmuwan populis, bukan sekedar ilmuwan tukang.

Memang tidak mudah mengubah "mindsef" (pandangan umum - paradigma) ilmuwan di manapun yang bertahun-tahun telah "dibentuk" pikiran dan otaknya melalui pendidikan formal, lebih-lebih apabila pendidikan itu sebagian besar terjadi di luar lingkungan budaya bangsanya. Bahkan jika pendidikan formal itu terjadi di negara sendiri, tetapi hampir $100 \%$ bahan-bahan studinya berasal dari luar, hasilnya akan sama, ilmuwan yang bersangkutan bisa jauh lebih akrab dengan cara berpikir "bukan Indonesia", dan akan merasa "terasing" dari cara berpikir Indonesia. Terhadap kesimpulan yang terakhir ini banyak pakar ekonomi Indonesia tidak sepakat, dan menyatakan dengan sengit "jangan pernah berpikir orang Indonesia unik, berbeda dariorang lain". Inilah awal dari skeptisisme ilmuwan Indonesia "modern" yang tidak lagi percaya pada ideologi Pancasila sebagai falsafah atau pandangan hidup bangsa. Dalam era globalisasi sekarang rupanya tidak ada lagi pengertian "nasionalisme" bagi pakar-pakar ekonomi yang sudah keblinger ini.

Demikian kita sedang menghadapi "krisis teori ekonomi", yaitu kekacauan cara berpikir para ekonom yang amat sulit mencapai kesepakatan apapun tentang aneka masalah ekonomi yang bermunculan dalam masyarakat-bangsa. Dalam masalahmasalah moneter, otonomi daerah, kemiskinan, dan pengangguran, meskipun teori ekonomi yang dipelajari sama, bersumber pada teori ekonomi Neoklasik Barat, tetapi hampir semua sama-sama tidak didukung data-data empirik, sehingga pendapat para pakar bisa berbeda amatjauh yang satu dari yang lain.

\section{Ekonomi Pasar dan Keadilan}

A theory however elegant and economical must be rejected or revised if it is untrue; likewise laws and institutions no matter how efficient and well-arranged must be reformed or abolished if they are unjust (Rawls, 2001:3).

Pancasila dasar negara kita mengajarkan (dan mengamanatkan) bahwa segala cara dan jalan harus ditempuh oleh pemerintah dan masyarakat Indonesia agar dapat terwujud suatu keadilan sosial bagi seluruh rakyat Indonesia. Setelah 59 tahun merdeka ternyata tujuan masyarakat adil dan makmur ini tidak mudah mewujudkannya.

Salah satu masalah besar yang kini kita hadapi yang berkaitan dengan keadilan adalah korupsi, dan nama "penyakit" ini kita lunakkan menjadi " $K K N$ ". Perubahan nama dari "korupsi" menjadi "KKN" ini barangkali cukup beralasan karena praktek korupsi terkait erat dengan koneksi dan nepotisme. Tetapi tidak dapat disangkal bahwa sesungguhnya dampak "penggantian" ini tidak positif karena " $K K N$ " terasa lebih ringan dan lebih mudah ditoleransi daripada "korupsi".

Kami pernah "menyamakan" penyakit ekonomi inflasi dan korupsi. ${ }^{3}$ Inflasi, yang telah menjadi hiperinflasi, berhasil diatasi dengan sangat sukses oleh para teknokrat kita tahun-tahun 1966-1969, tetapi sayangnya tidak ada tanda-tanda kita mampu dan mau mengatasi masalah korupsi

${ }^{3}$ Mubyarto, Social and Economic Justice, BIES, Special Issue, Vol XX. No. 3, December 1984, Hal. 36-54. 
sekarang, meskipun korupsi sudah benarbenar merebak mengerikan. Mengapa? Masalahnya adalah karena penyakit inflasi lebih bersifat teknis sehingga ilmu ekonomi sebagai monodisiplin mampu mengatasinya. Sebaliknya korupsi merupakan masalah sosial-budaya dan politik, sehingga ilmu ekonomi sendirian sama sekali tidak mampu mengatasinya. Lebih parah lagi ekonom malah cenderung tidak berani memusuhi korupsi karena sering ada kesan korupsi "tidak terlalu mengganggu pembangunan", atau pertumbuhan ekonomi seperti halnya inflasi juga dianggap "lebih menggairahkan" pembangunan. Meskipun mungkin tidak terlalu benar barangkali ada pula pemikiran ekonom yang mentoleransi korupsi karena justru ia (korupsi) dapat "memperluas pasar" bagi barang-barang mewah yang diproduksi atau diimpor. Jadi dunia usaha memang nampak lebih bergairah jika ada korupsi. Ini tentu saja merupakan pemikiran ekonomi yang keblinger.

Kiranya kunci dari pemecahan masalah korupsi adalah keberpihakan penuh dari pemerintah pada keadilan. Korupsi harus kita sepakati sebagai masalah yang amat menghambat upaya pewujudan keadilan sosial dan upaya pembangunan sosial dan pembangunan moral. Jika sekarang korupsi telah menghinggapi anggota-anggota legislatif di pusat dan di daerah-daerah, bahayanya harus dianggap jauh lebih parah karena mereka (anggota DPR/DPRD) adalah wakil rakyat. Jika wakil-wakil rakyat sudah "berjemaah" dalam berkorupsi, maka pasti tindakan ini tidak mewakili aspirasi rakyat banyak yang diwakilinya, tetapi hanya mewakili aspirasi pribadi/kelompoknya yang serakah.

Jika sejak krisis multidimensi yang berawal dari krismon 1997/1998 ada anjuran serius agar pemerintah mulai berpihak pada ekonomi rakyat (dan tidak lagi pada konglomerat), dalam bentuk program-program pemberdayaan ekonomi rakyat, maka ini berarti harus ada keadilan politik. Keadilan ekonomi dan keadilan sosial sejauh ini tidak ada atau tidak terwujud di Indonesia karena tidak dikembangkannya keadilan politik. Keadilan politik adalah "aturan main" berpolitik yang adil, atau menghasilkan keadilan bagi seluruh warga negara. Dan jika menurut John Rawls asas politik yang adil adalah minimal menaikkan posisi warga bangsa yang paling miskin/paling kurang beruntung, maka jelas pesan keadilan politik harus terwujud dalam bentuk menciutnya jurang kaya miskin dan terberantasnya kemiskinan di Indonesia.

Saya menghimbau rekan-rekan ilmuwan sosial, untuk bekerja lebih keras dan berpikir secara empirik-induktif, yaitu selalu mencoba menggunakan data-data empirik dalam berargumentasi, tidak hanya berpikir secara teoritis saja, lebih-lebih dengan selalu mengacu pada teori-teori Barat. Dengan berpikir empirik kesimpulankesimpulan pemikiran yang dihasilkan akan langsung bermanfaat bagi masyarakat dan para pengambil kebijakan masa sekarang. Misalnya tentang praktek kehidupan orangorang kaya di Indonesia. Adilkah orang-orang kaya kita hidup super mewah ketika pada saat yang sama masih sangat banyak warga bangsa yang harus mengemis sekedar untuk makan? Tentang penggunaan pendapatan, apakah dikonsumsi atau ditabung, John Rawls dengan saving principle-nya menyatakan,

Saving is demanded as a condition of bringing about full realizations of just institutions and the equal liberties.

The just saving principle can be regarded as an understanding between generations to carry their fair share of the burden of realizing a just society. 
It is a mistake to believe that a just and good society must wait upon a high material standard of life. What men want is meaningful work in free association with others (Rawls, 2001: 257).

Tentang mahalnya biaya pendidikan yang kini dibahas dengan "meriah" oleh masyarakat kita, kita perlu menganalisisnya dari segi yang lebih luas dan dengan sudut pandang keadilan. Benarkah dan adilkah kita tidak peduli pada kualitas pendidikan kita dan sekedar melihat pada tinggi rendahnya biaya SPP? Pengangguran yang selama ini kita keluhkan terutama pengangguran terdidik untuk sebagian besar bukan karena kurangnya lapangan kerja tetapi lebih karena tidak relevannya atau rendahnya kualitas pendidikan kita.

\section{Ace Partadiredja dan Ekonomi Pancasila}

Ekonom konvensional yang berpaham ekonomi neoklasik yang cenderung makin angkuh dengan alat-alat analisis matematikanya, sering mengejek ilmu ekonomi kelembagaan (institutional economics) sebagai "teori ekonomi tanpa teori". Artinya, karena "teori" ekonomi kelembagaan sangat mempertimbangkan nilai-nilai budaya atau ideologi suatu masyarakat-bangsa, maka menurut mereka teori ekonomi yang sudah bersifat "universal" jangan dihilangkan ke"universalan"nya. Ini berarti, menurut mereka, ekonomi kelembagaan menggambarkan satu kemunduran.

Untuk menjawab kritik yang demikian ekonom J.R. Commons dari Universitas Wisconsin (1904) mengatakan adanya perbedaan tegas antara ekonomi arus utama dengan ekonomi kelembagaan sebägai berikut:

Institutional economics, however, embodied a certain philosophy that conflicted with the contemporary economic thinking. The methods used were based on a certain conception of human and economic behavior... Istitutional economics is an approach that regards the conflict rather that the harmony of interest as basic to economic behavior. It "avowed scarcity, insteads of taking it for granted", and hold that of scarcity "derives not only conflict but also to collective action that sets up order on account of mutual dependence. Institutional economics regards efficiency universal principle, because it overcomes scarcity by cooperation... (which) does not arise from presupposed harmony of interest.... it arises from the necessity of creating a new harmony of interests.

(Ekonomi kelembagaan, bagaimanapun juga mengandung filsafat tertentu yang bertentangan dengan pemikiran ekonom kontemporer. Cara-cara yang dipergunakan didasarkan pada pengertian tertentu tentang manusia dan perilaku ekonomi. ... ekonomi kelembagaan adalah sebuah pendekatan yang cenderung lebih memandang pertentangan dan bukan keserasian berbagai kepentingan yang menjadi dasar perilaku ekonomi. la "mengakui" kelangkaan tidak sebagai sesuatu yang diberikan begitu saja dan berpegang teguh bahwa dari kelangkaan itu dapat diturunkan tidak hanya pertentangan tetapi juga usaha bersama membangun tatanan atas dasar perhitungan saling menguntungkan. Ekonomi kelembagaan mengakui efisiensi sebagai sebuah prinsip umum, sebab ia mengatasi kelangkaan dengan kerja sama.... la muncul dari kebutuhan untuk menciptakan sebuah keharmonisan baru dari berbagai kepentingan. (Mubyarto 1995:38) 
Sebagai ekonom kelembagaan Prof. Ace Partadiredja menolak teori ekonomi neoklasik Barat yang "tidak bermoral" karena mengajarkan "keserakahan atas alam benda". Maka dalam pidato pengukuhan Guru Besar tahun 1981 secara spesifik ia mengharapkan ekonomi Pancasila sebagai ilmu ekonomi baru seharusnya dikembangkan di indonesia.

Harapan saya yang tertinggi adalah munculnya suatu ilmu ekonomi yang tidak memberikan kesan sebagai ilmu yang mengajarkan keserakahan atas alam benda, dan tidak memberikan kesan sebagai suatu ilmu yang mekanistik, melainkan sebagai suatu ilmu yang tidak hanya modelmodelnya relevan tapi juga model-model itu didasarkan pada asumsi yang realistik, etik, dan berwajah kemanusiaan yang dijwai oleh etika, ekonomika etik (ethical economics) sebagaimana ekonomi politik pada saat dilahirkannya pada abad 18. Mungkin ilmu baru itu dapat dinamai Ekonomika Pancasila. (Mubyarto, 2004: 18)

Judul pidato pengukuhan Ace adalah Ekonomika Etik, yaitu ilmu ekonomi yang benar-benar tidak sekedar mengajarkan efisiensi dan maksimisasi, tetapi sekaligus mampu mengajarkan manusia bertindak benar dan adil. Implikasi pandangan Ace ini jauh dan mendalam, karena berarti ilmu ekonomi tidak hanya mengajarkan perilaku manusia sebagai homo ekonomikus tetapi juga sebagai homo sosius dan homo etikus. Kita ekonom abad 20 dan 21, banyak yang tidak menyadari bahwa Adam Smith telah menulis buku The Theory of Moral Sentiments (1759) sebelum menulis The Wealth of Nations (1776). Kebanyakan pakar ekonomi menganggap Adam Smith dalam kurun waktu 17 tahun telah "berubah pikiran", padahal yang benar, setiap manusia memang memiliki 3 sifat dasar itu yaitu homo ekonomikus, homo sosius, dan homo etikus.
He is certainly not a good citizen who does not wish to promote, by every means of his power, the welfare of the whole society of his fellow-citizens. (Adam Smith, 1759) ${ }^{4}$

\section{Ekonom Indonesia Perlu Kembali ke Fitrah}

Teknokrat indonesia yang telah berjasa memajukan ekonomi Indonesia menjadi seperti kondisinya sekarang dengan pendapatan perkapita lebih dari US $\$ 1000$ dari kondisi 40 tahun lalu yang di bawah US\$ 100 , kini perlu dengan jujur mengakui kekeliruan-kekeliruannya. Jika Mahbub-UI Haq sebagai ekonom utama Pakistan merasa menyesal dan "mengaku dosa" karena telah membantu "memecah" Pakistan menjadi 2 negara (Pakistan sekarang dan Bangladesh) tahun 1971, maka teknokrat Indonesia perlu mawas diri pula, apakah "kekacauan ekonomi" sekarang yang berawal dari krismon 1997/1998, seharusnya tidak terjadi kalau "sistem ekonomi Pancasila" yang harus dibina pada tahun 1966 benar-benar dipatuhi aturanaturan mainnya. Kalau Emil Salim pada waktu itu berpendapat hanya sila ke-5 Pancasila yang relevan dalam mewujudkan perekonomian yang demokratis dan berkeadilan sosial, kini harus disadari mutlak perlunya sila-sila ke-1, 2, dan 3 dijadikan pedoman perilaku semua aktor ekonomi Indonesia. Sila ke-1 adalah dasardasar moral atau etik, sila ke-2 dasar-dasar kemanusiaan yang adil dan beradab, dan sila ke-3 adalah dasar kebangsaan atau nasionalisme.

${ }^{4}$ Muller, Jerry Z., 1993, Adam Smith in His Time and Ours, Princetown University Press, Princetown, hal: vii 
Dan Allah memberi rezeki kepada siapa yang dikehendakiNya tanpa batas (An Nuur. 38)

Allah-lah yang menciptakan kamu dan kemudian memberi rezeki (ArRuum: 40) Jika kita percaya dan mematuhi ke-2 firman Allah ini, maka kita harus mengkaji ulang ajaran "alat pemenuhan kebutuhan manusia (rezeki) terbatas", sedangkan "kebutuhan manusia tidak terbatas". Bukankah keserakahan manusia ini yang justru diajarkan dalam ekonomi kapitalis liberal dari Barat? Menurut ajaran agama, kebutuhan manusia harus dibatasi/ dikendalikan bukan dibawa ke arah kepuasan maksimum atau keuntungan yang sebesar-besarnya. Apabila ajaran ekonomi kini tidak lagi ditekankan pada "serba keterbatasan" tetapi pada "serba kelimpahan", maka perilaku ekonomi manusia harus berubah dari persaingan untuk mencapai kepuasan/keuntungan maksimum individual ke arah kemakmuran bersama melalui keadilan distribusi. Inilah demokrasi ekonomi yang didefinisikan dengan baik dalam penjelasan UUD 1945, yang telah dihilangkan "dengan semena-mena" oleh MPR melalui 4 kali amandemen selama 2001-2002. Yang benar, dalam kehidupan ekonomi harus ditekankan perlunya kerjasama untuk membagi-bagi sumber daya/rezeki yang telah disediakan melimpah itu, oleh Tuhan, secara adil. Kehidupan ekonomi harus kooperatif tidak bersaing saling mematikan.

Demikian ekonom Indonesia harus diakui telah terperosok ke jalan yang sesat, sehingga perlu kembali ke fitrah atau mengambil jalan yang benar.

\section{Penutup}

Ketika pada tahun 1969 di Malaysia timbul huru-hara karena konflik antara etnik
Cina dan Melayu, kita di Indonesia juga pernah mengalaminya pada tahun 1963 , tahun 1974, dan lebih hebat lagi tahun 1998. Namun bedanya jika pemerintah Malaysia kemudian menyusun politik ekonomi baru (New Economic Policy) yang secara sengaja dan transparan memihak kelompok ekonomi Bumiputera agar tidak tertinggal dari kelompok etnik Cina, kita di Indonesia berusaha "menyembunyikan" konflik etnik tersebut dan berusaha untuk "melupakannya". Jalan pikiran kita yang keliru biasanya adalah "jangan membesar-besarkan perbedaan atau konflik etnik itu, karena kebhinekaan itulah justru letak kekuatan bangsa Indonesia". Memang benar semboyan kita adalah "Bhinneka Tunggal Ika", tetapi benarkah kita tidak perlu secara sungguh-sungguh berusaha secara ekonomi-politik mengurangi atau menciutkan jurang itu? Tidakkah akan keliru kalau kita justru berpihak pada kelompok ekonomi kuat meskipun dengan menghimbau mereka untuk 'meneteskan rezeki' mereka kepada golongan ekonomi (pribumi) yang lemah. Kini sudah banyak disebutkan ketidakbenaran teori "trickle down effect." Kebijakan pemihakan pemerintah kepada para konglomerat/ pemodal besar yang berse-kongkol dengan investor asing jelas mengakibatkan terjadinya proses trickle up.

Berhubung dengan itu adalah wajar dan adil jika kini pemerintah benar-benar harus melaksanakan kebijakan ekonomi yang populis, yang memihak pada kelompok miskin ekonomi lemah, yang secara keseluruhan termasuk dalam ekonomi rakyat. Ekonomi rakyat terdiri atas mereka yang bekerja mandin yang berusaha menciptakan pekerjaan sendiri (self-employment) bukan keja upahan (wageemployment), yang hanya dapat diciptakan pengusaha-pengusaha besar dengan menggunakan kreditbank. Ilmu ekonomiyang tepat dan relevan bagi mahasiswa Indonesia 
adalah ekonomi pasar yang berpihak pada rakyat banyak, ekonomi pasar-populis.

\section{Daftar Pustaka}

Etzioni, Amitai, 1988, The Moral Dimension: Toward A New Economics, New York: The Free Press.

Galston, William A., 1980, Justice and The Human Good: University of Chicago, Press, Chicago.

Kuttner, Robert, 1984, The Economic Illusion: False Choices Between Prosperity and Social Justice, Pennsylvania University of Press.

Kymlicka, Will, 1990, Contemporary Political Philosophy: An Introduction, Oxford: Clarendon Press .

Mubyarto, 1995, Ekonomi dan Keadilan Sosial,Yogyakarta: Aditya Media.

Mubyarto \& Daniel W. Bromley, 2002, A Development Alternative for Indonesia, Yogyakarta: Gadjah Mada University Press.

Mubyarto, 2004, Pancasila Dasar Negara, UGM, dan Jati Diri Bangsa, Yogyakarta: Aditya Media.

2004, Teori Ekonomi dan Kemiskinan, Yogyakarta: Aditya Media.

2004, Teknokrat dan Ekonomi Pancasila, Yogyakarta: Aditya Media.

2004, Neoliberalisme dan Krisis IImu Ekonomi, Aditya Media, Yogyakarta.
2004, Revolusi menuju Sistem Ekonomi Pancasila, Yogyakarta: Aditya Media.

2004, Gagasan Besar Ekonomi dan Kemajuan Kemanusiaan, Yogyakarta: Aditya Media.

2004, Pancasila Dasar Negara, UGM, dan Jati Diri Bangsa, Yogyakarta: Aditya Media.

Nelson, Robert $\mathrm{H}, 2001$, Economics As Religion: from Samuelson to Chicago and Beyond, Pennsylvania: The Pennsylvania State University Press.

Ormerod, Paul., 1994, The Death of Economics. New York: Urizen Books.

Partadiredja, Ace, 2000, Ekonomika Etik, Pidato Pengukuhan Guru Besar IImu Sosial, Yogyakarta: Gadjah Mada Press.

Troy P.N. (ed), 1981, A Just Society?, George Allen \& Unwin, Sydney.

Yunus, Muhammad, 2003, Halving Poverty by 2015: We Can Actually Make It Happen, Cittagong, Bangladesh: Packages Corporation Limited .

2003, Some Suggestions on Legal Framework for Creating Microcredit Banks, Cittagong, Bangladesh:Packages Corporation Limited.

2003, Expanding Microcredit Outreach to Reach the Millennium Development Goal-Some Issues for Attention, Cittagong, Bangladesh: Packages Corporation Limited. 